Article

\title{
Effects of Ultrasound on Zinc Oxide/Vermiculite/Chlorhexidine Nanocomposite Preparation and Their Antibacterial Activity
}

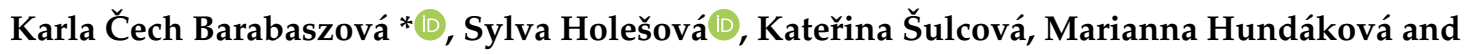 \\ Barbora Thomasová \\ Nanotechnology Centre, VSB-Technical University of Ostrava, 17. listopadu 15/2172, 70800 Ostrava-Poruba, \\ Czech Republic; sylva.holesova@vsb.cz (S.H.); katerina.sulcova.st@vsb.cz (K.Š.); \\ marianna.hundakova@vsb.cz (M.H.); barbora.thomasova@vsb.cz (B.T.) \\ * Correspondence: karla.cech.barabaszova@vsb.cz; Tel.: +420-0596-991-572
}

Received: 16 August 2019; Accepted: 10 September 2019; Published: 13 September 2019

check for updates

\begin{abstract}
Microbial infection and biofilm formation are both problems associated with medical implants and devices. In recent years, hybrid organic-inorganic nanocomposites based on clay minerals have attracted significant attention due to their application potential in the field of antimicrobial materials. Organic drug/metal oxide hybrids exhibit improved antimicrobial activity, and intercalating the above materials into the interlayer of clay endows a long-term and controlled-release behavior. Since antimicrobial activity is strongly related to the structure of the material, ultrasonic treatment appears to be a suitable method for the synthesis of these materials as it can well control particle size distribution and morphology. This study aims to prepare novel, structurally stable, and highly antimicrobial nanocomposites based on zinc oxide/vermiculite/chlorhexidine. The influence of ultrasonic treatment at different time intervals and under different intercalation conditions (ultrasonic action in a breaker or in a Roset's vessel) on the structure, morphology, and particle size of prepared hybrid nanocomposite materials was evaluated by the following methods: scanning electron microscopy, X-ray diffraction, energy dispersive X-ray fluorescence spectroscopy, carbon phase analysis, Fourier transforms infrared spectroscopy, specific surface area measurement, particle size analysis, and Zeta potential analysis. Particle size analyses confirmed that the ultrasonic method contributes to the reduction of particle size, and to their homogenization/arrangement. Further, $\mathrm{X}$-ray diffraction analysis confirmed that ultrasound intercalation in a beaker helps to more efficiently intercalate chlorhexidine dihydrochloride $(\mathrm{CH})$ into the vermiculite interlayer space, while a Roset's vessel contributed to the attachment of the $\mathrm{CH}$ molecules to the vermiculite surface. The antibacterial activity of hybrid nanocomposite materials was investigated on Gram negative (Escherichia coli, Pseudomonas aeruginosa) and Gram positive (Staphylococcus aureus, Enterococcus faecalis) bacterial strains by finding the minimum inhibitory concentration. All hybrid nanocomposite materials prepared by ultrasound methods showed high antimicrobial activity after $30 \mathrm{~min}$, with a long-lasting effect and without being affected by the concentration of the antibacterial components zinc oxide $(\mathrm{ZnO})$ and $\mathrm{CH}$. The benefits of the samples prepared by ultrasonic methods are the rapid onset of an antimicrobial effect and its long-term duration.
\end{abstract}

Keywords: ultrasonic intercalation; mechanical stirring; zinc oxide nanoparticles; vermiculite; chlorhexidine; antibacterial activity

\section{Introduction}

Currently, many different methods and processes (hydrothermal, chemical coprecipitation [1], sol-gel synthesis, and sonochemical and mechanochemical synthesis, etc.) are used for nanocomposite 
material preparation. Hybrid antibacterial nanocomposite materials are specific examples of nanocomposite materials, which are increasingly in demand, especially in the fields of medicine, biomedical, and food applications [2,3].

Hybrid nanomaterials, formed by two or more components with at least one component being at the nanometric dimension, combine the intrinsic characteristics of their individual constituents to give additional properties due to the synergistic effects between the components. The main reason why these individual components are connected together is to combine their most favorable properties with one another and at the same time to eliminate the disadvantages of each component [4]. The preparation of hybrid nanocomposite materials is itself very difficult and demanding. Complications are mainly caused by a large difference in the working temperatures of the individual organic and inorganic components. Organic nanomaterials are typically treated at ambient temperatures up to $200{ }^{\circ} \mathrm{C}$, in contrast to inorganic nanomaterials that require higher temperatures. Therefore, the appropriate choice of method and preparation conditions is a key element in the final nature of the material $[5,6]$.

The ultrasonic method is widely used as an efficient and practical way for the preparation of a huge range of materials with controlled properties. Ultrasonic treatment is considered to be a method where either the crystal structure is not or is only minimally disrupted [7]. The main advantage of ultrasonic treatment lies in the versatility by which nanostructured metals, oxides, chalcogenides, carbides, polymers, and nanocomposite materials can be prepared. Ultrasonic treatment is also important for the preparation of micron and submicron particles of layered clay minerals. Under the influence of ultrasound, the clay mineral is exposed to thermal shock and steam generation in the interlayer, and subsequent exfoliation of individual layers occurs. 2:1 phyllosilicates, which in an exfoliated state exhibit low bulk density, thermal conductivity, and a relatively high melting point, are most commonly used for this method. The size of the synthesized particles is closely related to the length of the processing time [8,9]. A change of working conditions can also have a significant effect on both the preparation process and the resulting character of the material. Efficient utilization of the Roset type reactor has been studied in the preparation of Na-vermiculite micron particles [10]. The most noticeable effect on particle size is the change in temperature, where, with increasing temperature $\left(90^{\circ} \mathrm{C}\right)$, the particle size and span of time rapidly decrease. An effective particle reduction process is due to exfoliation and delamination of particles as a result of cavitation and evaporating water bubbles at higher temperatures. Longer exposure to ultrasound under these conditions leads to particle size growth due to aggregation and subsequent deagglomeration. Ultrasonic treatment can also be effectively used for intercalation, e.g., polyethylene glycol into the montmorillonite structure. Intercalation also reduces the montmorillonite particles without destroying the crystal structure [11].

The development of suitable antibacterial materials that can be used for medical purposes is a current medical research topic. Substances that act as carriers of antibacterial or antifungal agents for topical treatment that avoid undesirable treatment of the entire body are of particular interest [12]. For practical applications, sustained antibacterial activity with regular drug release is desirable. Antibacterial agents can be divided into two categories, based on their chemical composition: organic and inorganic. Organic antibacterial materials are often less stable, especially at high temperatures and pressures, and they tend to evaporate or decompose. On the other hand, they possess organophilicity, so it is easy for them to adhere to and exterminate microbes. Inorganic antibacterial agents that have prolonged exposure times, chemical stability, and heat resistance are receiving increasing attention. In particular, metal ions and oxides of silver $\left(\mathrm{Ag}^{+}\right)$, zinc $\left(\mathrm{Zn}^{2+}\right)$, or copper $\left(\mathrm{Cu}^{2+}\right)$, which effectively inhibit the birth and growth of harmful microbes, are currently used $[13,14]$. Sustained antibacterial activity with a regular release of nanomaterial drugs is also not negligible. The antibacterial activity of zinc oxide nanoparticles depends primarily on particle size, particle specific surface area, and concentration [15-19]. The most significant antibacterial activity of zinc oxide nanoparticles is reported against Escherichia coli and Staphylococcus aureus bacterial strains. Nowadays, clay minerals such as smectites (montmorillonite, saponite), talc, or kaolinite are frequent carriers of antibacterial agents 
(drugs). Layered silicates have become a part of biological systems due to their inertia and non-toxic character [20].

Vermiculite (2:1 layered silicates) is one of the naturally occurring clay silicate minerals with layers built up of one octahedral sheet sandwiched between two tetrahedral sheets. The central cations of octahedra (ideally $\mathrm{Al}^{3+}$ ) and tetrahedra (ideally $\mathrm{Si}^{4+}$ ) can be substituted by cations. These substitutions result in a negative layer charge on the silicate layers. Space between layers (interlayer space) is occupied by exchangeable hydrated cations such as $\mathrm{Mg}^{2+}, \mathrm{Ca}^{2+}, \mathrm{Na}^{+}, \mathrm{K}^{+}$, etc., compensating the negative layer charge. The magnitude of layer charge on the vermiculite layers has a key effect on the amount of intercalated organic molecules and on their arrangement in the interlayer space.

Vermiculite does not exhibit antibacterial activity [21] but does adsorb and kill bacteria as soon as their structure is intercalated by an antibacterial agent. Very good results of the antibacterial activity of chlorhexidine in a vermiculite structure have been demonstrated with a nanocomposite material that was prepared by an ion exchange reaction. The efficacy against $S$. aureus was confirmed by samples with the lowest chlorhexidine concentration, and the activity was proven even after prolonged exposure. The results also showed that even the highest chlorhexidine dihydrochloride $(\mathrm{CH})$ concentration used did not lead to the complete intercalation and destruction of the vermiculite crystal structure [12].

In this work, we have investigated the preparation conditions of the hybrid nanocomposite based on zinc oxide/vermiculite/chlorhexidine derived by ultrasound treatment. The aim was to prepare a structurally stable and highly antibacterial nanomaterial with a defined concentration composition of organic and inorganic components.

\section{Materials and Methods}

\subsection{Materials and Nanocomposites Preparation}

Natural Mg-vermiculite from Brazil (supplied by Grena Co., Veselí nad Lužnicí, Czech Republic) was used as a starting material for the nanocomposite sample preparation. Natural vermiculite was milled in a planetary ball mill (Retsch PM4) and then sieved through a $0.040 \mathrm{~mm}$ sieve (sample named V).

The zinc oxide/vermiculite $(\mathrm{ZnO} / \mathrm{V})$ nanocomposite was prepared by the sonochemical method in $1 \mathrm{M} \mathrm{NaCl}$ solution followed by a heat treatment. The required amount of $\mathrm{NaCl}$ was dissolved in $100 \mathrm{~mL}$ of distilled water and heated on an electric heater to $80^{\circ} \mathrm{C}$. Five grams of vermiculite, $2.5 \mathrm{~g}$ of anhydrous $\mathrm{ZnCl}_{2}$, and $2.5 \mathrm{~g}$ of anhydrous $\mathrm{Na}_{2} \mathrm{CO}_{3}$ (all from Sigma Aldrich) were gradually added to the solution. The titanium sonotrode (UP100H from Hielscher, Teltow, Germany) was placed in the suspension and sonicated for $15 \mathrm{~min}$ throughout the cycle at 50\% amplitude. Subsequently, the sample was washed with distilled water and centrifuged until chlorides disappeared. The solid nanocomposite material was dried and homogenized. The homogenized sample was calcined at $350{ }^{\circ} \mathrm{C}$ for $1.5 \mathrm{~h}$. The sonochemically prepared inorganic nanocomposite sample was designated $\mathrm{ZnO} / \mathrm{V}$.

The $\mathrm{ZnO} / \mathrm{V} / \mathrm{CH}$ nanocomposites were prepared by the intercalation of chlorhexidine dihydrochloride $(\mathrm{CH})$ using two different techniques-mechanical stirring and ultrasonic action.

During mechanical stirring, $2 \mathrm{~g}$ of the $\mathrm{ZnO} / \mathrm{V}$ nanocomposite was mixed in $50 \mathrm{~mL}$ of demineralized water for $3 \mathrm{~min}$ and was then added to the $50 \mathrm{~mL}$ ethanol solution, in which $2 \mathrm{~g}$ of $\mathrm{CH}$ had been previously dissolved. The dispersions were homogenously mixed for $5 \mathrm{~h}$ at $75^{\circ} \mathrm{C}$ on a magnetic stirrer. The final dispersion was freed from water by centrifugation and drying at $75^{\circ} \mathrm{C}$ for $24 \mathrm{~h}$. The hybrid nanocomposite material was named $\mathrm{ZnO} / \mathrm{V} \_\mathrm{M} \_\mathrm{CH}$.

Identical chemical precursors were used for ultrasonic intercalation. The ultrasonic titanium sonotrode was placed in the dispersion in a beaker, and the mixture was subjected to ultrasound treatment at 30 and $90 \mathrm{~min}$ intervals. The dispersion was subsequently centrifuged and dried at $75^{\circ} \mathrm{C}$ for $24 \mathrm{~h}$ (hybrid nanocomposite samples were named $\mathrm{ZnO} / \mathrm{V} \_30 \mathrm{UCH}$ and $\mathrm{ZnO} / \mathrm{V} \_90 \mathrm{UCH}$ ). Under the same conditions, dispersions were subjected to ultrasound treatment in a Roset's vessel (hybrid nanocomposite samples were named $\mathrm{ZnO} / \mathrm{V} \_30 \mathrm{UCH}$ _R and $\left.\mathrm{ZnO} / \mathrm{V} \_90 \mathrm{UCH} \mathrm{R}\right)$. 


\subsection{Analytical Methods and Equipment}

The chemical composition of vermiculite $(\mathrm{V})$ and the hybrid nanocomposite samples was obtained from elemental analysis by X-ray fluorescence spectroscopy (SPECTRO XEPOS new energy dispersive $\mathrm{X}$-ray fluorescence spectrometer).

The morphology of the nanocomposite samples was investigated using scanning transmission electron microscope (STEM) JEOL JSM-7610F Plus, Tokyo, Japan. The samples were coated with a gold/palladium film in order to avoid problems with electrical charging. SEM images were obtained using a scattered electron detector (SE, LEI).

The X-ray powder diffraction (XRD) analysis was performed using the diffractometer RIGAKU Ultima IV (scintilation detector, $\mathrm{CuK} \alpha$ radiation, $\mathrm{NiK} \beta$ filter, Bragg-Brentano arrangement, Tokyo, Japan. Samples in a standard holder were measured in ambient atmosphere $\left(40 \mathrm{kV}, 40 \mathrm{~mA}, 2.32^{\circ} / \mathrm{min}\right)$. Phase analysis was evaluated by database PDF-2 Release 2011.

The organic carbon content in the hybrid nanocomposite samples was determined using phase carbon analyzer RC612 (LECO, MI, USA). The defined weight of the hybrid nanocomposite samples was found by burning them in an oxygen atmosphere with a temperature range of $100^{\circ} \mathrm{C}$ to $1000^{\circ} \mathrm{C}$. The carbon was detected in the IR cells in the form of $\mathrm{CO}_{2}$.

The IR spectra of the original $\mathrm{V}, \mathrm{ZnO} / \mathrm{V}$, and hybrid nanocomposite samples were obtained using the potassium bromide pellets technique. Exactly $1.0 \mathrm{mg}$ of each sample was ground with $200 \mathrm{mg}$ of dried potassium bromide. This mixture was used to prepare the potassium bromide pellets. The pellets were pressed under 8 tons for $30 \mathrm{~s}$ under vacuum. The IR spectra were collected using FTIR (spectrometer Nexus 470 (ThermoScientific, MA, USA) with a DTGS detector. The measurement parameters were as follows: spectral region, $4000-400 \mathrm{~cm}^{-1}$; spectral resolution, $4 \mathrm{~cm}^{-1}, 64$ scans; Happ-Genzel anodization. Treatment of spectra: polynomial (second order) baseline, subtraction spectrum of pure potassium bromide.

The particle size of all samples was determined by the HORIBA Laser diffraction particle size analyser (LA-950 instrument, Kyoto, Japan) with a short-wavelength blue and red light source in conjunction with forward and backscatter detection. The particle size analyses were conducted with refractive indices of 1.54 (for vermiculite), 1.50 (for zinc oxide), 1.54 (for chlorhexidine), and 1.33 (for water).

Zeta potential ( $\xi$-potential) was measured by a nanoparticle analyzer (HORIBA Nanopartica SZ-100, Kyoto, Japan) equipped with a microprocessor unit to directly calculate the $\xi$-potential. The system measures the sample conductivity, applies an electric field, and then measures the motion of the particles using electrophoretic light scattering. Each sample $(0.5 \mathrm{~g})$ was mechanically mixed with $50 \mathrm{~mL}$ of distilled water. One milliliter of the suspension was introduced into the disposable zeta potential cell. The $\xi$-potential was measured at natural $\mathrm{pH}$. Each data point was an average of approximately 6 measurements. All measurements were made at ambient temperature $\left(24.9^{\circ} \mathrm{C}\right)$, conductivity $\left(0.194 \mathrm{mS}^{-\mathrm{cm}^{-1}}\right)$, suspension viscosity $(0.93 \mathrm{mPa} . \mathrm{s})$, and electrode voltage constant $(3.4 \mathrm{~V})$. The $\xi$-potential was calculated using the Smoluchowski equation.

Specific surface area (SSA) was measured at liquid nitrogen atmosphere by means of a thermo scientific surfer. Prior to measurements, the samples were degassed under vacuum $\left(10^{-6}\right.$ bar $)$ at $120^{\circ} \mathrm{C}$ for $24 \mathrm{~h}$. The SSA was calculated using the BET (Brunauer-Emmett-Teller) equation by assuming the area of the nitrogen molecule was $0.1620 \mathrm{~m}^{2}$. The total pore volume (PV) was obtained from the maximum amount of nitrogen gas adsorbed at partial pressure $\left(p / p^{0}\right)=1$.

\subsection{Antibacterial Tests}

The antibacterial activity of the samples was tested against four different human pathogenic strains; Gram negative strains (Escherichia coli, CCM 3954 and Pseudomonas aeruginosa, CCM 3955) and Gram positive strains (Staphylococcus aureus, CCM 3953 and Enterococcus faecalis, CCM 4224). The results were determined using a standard microdilution method, which enables the determination of 
the minimum inhibitory concentration (MIC) that completely inhibits bacterial growth in accordance with their lowest concentration.

The dilution and cultivation were performed on a microtitration plate with 96 hollows. The first set of hollows on the plate contained $10 \%(w / v)$ sample water dispersions. These dispersions were further diluted by a threefold diluting method in glucose stock in such a manner that the second to seventh sets of hollows contained samples dispersed in concentrations of $5 \%, 1.67 \%, 0.56 \%, 0.19 \%$, $0.062 \%, 0.021 \%$, and $0.007 \%$. The eighth set of hollows contained pure glucose stock as a control test. A volume of $1 \mu \mathrm{L}$ of glucose suspensions of E. coli $\left(1.5 \times 10^{9} \mathrm{CFU} \mathrm{m}^{-1}\right)$, P. aeruginosa $\left(1.7 \times 10^{9} \mathrm{CFU} \mathrm{ml}^{-1}\right)$, S. aureus $\left(1.7 \times 10^{9} \mathrm{CFU} \mathrm{ml}^{-1}\right)$, and E. faecalis $\left(1.6 \times 10^{9} \mathrm{CFU} \mathrm{ml}^{-1}\right)$, provided by the Czech collection of microorganisms (CCM), was put into the hollows. Bacterial suspensions, after the elapse of 30, 60, 90, 120, 180, 240 and $300 \mathrm{~min}$, and then over 2 days at $12 \mathrm{~h}$ intervals, were transferred from each hollow to $100 \mu \mathrm{L}$ of the fresh glucose stock and bacteria, and were incubated in a thermostat at $37^{\circ} \mathrm{C}$ for 24 and $48 \mathrm{~h}$. Antibacterial activity was evaluated by turbidity, which is a display of bacterial growth.

\section{Results}

\subsection{X-ray Fluorescence Analysis}

The changes in the chemical composition from the elemental analysis of all experimental samples were calculated to the stoichiometric metal oxide concentrations and are summarized in Table 1. Mechanical and ultrasonic processing of nanocomposite particles leads to chemical changes, mostly in $\mathrm{SiO}_{2}, \mathrm{Al}_{2} \mathrm{O}_{3}, \mathrm{Fe}_{2} \mathrm{O}_{3}$, and $\mathrm{MgO}$ contents [22].

Table 1. The chemical composition (wt \%) and organic carbon content $\left(f_{\text {oc }}\right)$ of the $\mathrm{V}, \mathrm{ZnO} / \mathrm{V}$, ZnO/V_M_CH, ZnO/V_30U_CH, ZnO/V_90U_CH, ZnO/V_30U_CH_R, and ZnO/V_90U_CH_R nanocomposite samples.

\begin{tabular}{|c|c|c|c|c|c|c|c|}
\hline Samples & $\mathbf{V}$ & $\mathrm{ZnO} / \mathrm{V}$ & ZnO/V_M_CH & ZnO/V_30U_CH & ZnO/V_90U_CH & ZnO/V_30U_CH_R & ZnO/V_90U_CH_R \\
\hline$f_{\mathrm{oc}}$ & - & - & 13.86 & 22.59 & 27.44 & 27.62 & 26.42 \\
\hline $\mathrm{ZnO}$ & - & 23.57 & 20.44 & 14.87 & 13.82 & 12.87 & 13.74 \\
\hline $\mathrm{SiO}_{2}$ & 40.70 & 33.54 & 23.66 & 18.52 & 14.7 & 14.48 & 15.83 \\
\hline $\mathrm{Al}_{2} \mathrm{O}_{3}$ & 10.10 & 8.50 & 7.21 & 6.66 & 5.74 & 5.97 & 6.18 \\
\hline $\mathrm{Fe}_{2} \mathrm{O}_{3}$ & 9.28 & 6.56 & 5.22 & 3.54 & 3.38 & 3.08 & 3.30 \\
\hline $\mathrm{CaO}$ & 1.75 & 1.00 & 0.69 & 0.50 & 0.43 & 0.36 & 0.45 \\
\hline $\mathrm{MgO}$ & 17.80 & 17.64 & 12.87 & 12.80 & 10.03 & 11.58 & 12.37 \\
\hline $\mathrm{MnO}$ & 0.10 & 0.09 & 0.07 & 0.05 & 0.05 & 0.04 & 0.04 \\
\hline $\mathrm{Na}_{2} \mathrm{O}$ & 0.60 & $<1$ & $<1$ & $<1$ & $<1$ & $<1$ & $<1$ \\
\hline $\mathrm{K}_{2} \mathrm{O}$ & 2.76 & 1.85 & 1.49 & 1.02 & 0.95 & 0.86 & 0.91 \\
\hline $\mathrm{Cl}$ & - & 0.10 & 7.32 & 12.75 & 16.51 & 16.50 & 13.85 \\
\hline
\end{tabular}

The initial weight composition of the $\mathrm{ZnO}$ in the sonochemically prepared $\mathrm{ZnO} / \mathrm{V}$ nanocomposite was $23.57 \mathrm{wt} \%$. The mechanical intercalation of $\mathrm{CH}$ caused a decrease in the $\mathrm{ZnO}$ composition to $20.44 \mathrm{wt} \%$ (ZnO/V_M_CH), while ultrasonic intercalation led to a decreased composition from $23.57 \mathrm{wt} \%$ to $14.87 \mathrm{wt} \%\left(\mathrm{ZnO} / \mathrm{V} \_30 \mathrm{U} \_\mathrm{CH}\right)$ and to $12.87 \mathrm{wt} \%\left(\mathrm{ZnO} / \mathrm{V} \_30 \mathrm{U} \_\mathrm{CH} \_\mathrm{R}\right)$. The chemical composition of the other oxides was also adequately reduced.

The values of organic carbon content $\left(f_{\mathrm{oc}}\right)$ predicted and confirmed the level of $\mathrm{CH}$ intercalation in the hybrid nanocomposites (Table 1). The results show that the lowest carbon content $(13.86 \mathrm{wt} \%)$ have mechanically intercalated the nanocomposite sample ( $\left.\mathrm{ZnO} / \mathrm{V} \_\mathrm{M} \_\mathrm{CH}\right)$. Conversely, the highest $f_{\text {oc }}$ value (27.62 wt \%) was measured for the $\mathrm{ZnO} / \mathrm{V} \_30 \mathrm{U} \_\mathrm{CH}$ _R sample, prepared in a Roset's vessel after 30 min of ultrasound treatment. Higher concentrations of chlorides in hybrid nanocomposites also confirmed a higher rate of intercalation by ultrasonic processes.

From XRFS analysis, it can be assumed that during the mechanical intercalation of $\mathrm{CH}$ weak mechanical/friction forces are exerted, which do not significantly affect the $\mathrm{ZnO}$ amount in the structure of the nanocomposite material ( $\left.\mathrm{ZnO} / \mathrm{V} \_\mathrm{M} \_\mathrm{CH}\right)$. Conversely, the ultrasonic intercalation of $\mathrm{CH}$ due to the strong cavitation effect causes both surface disruption of the vermiculite particles and disruption of 
the bonds between the $\mathrm{ZnO}$ nanoparticles and $\mathrm{V}$. It can be assumed that this process contributes to the emergence of new areas where higher amounts of $\mathrm{CH}$ are anchored.

\subsection{Nanocomposite Particles Morphology}

The morphological changes of nanocomposite samples are evident from the scanning transmission electron images (Figure 1). It is known that the natural V samples are formed by the particles with irregular shapes and sizes and smooth lamellar morphologies [22]. The ZnO nanoparticles in sonochemically prepared $\mathrm{ZnO} / \mathrm{V}$ nanocomposites (Figure 1a) are widely dispersed on the surfaces and mainly decorate the V particle's edges [20]. Smaller particle fractions, which are agglomerated together and are in contact with bigger fractions by the particle edges, are present in the volume. The $\mathrm{ZnO} / \mathrm{V}$ nanocomposite particles intensively agglomerated.
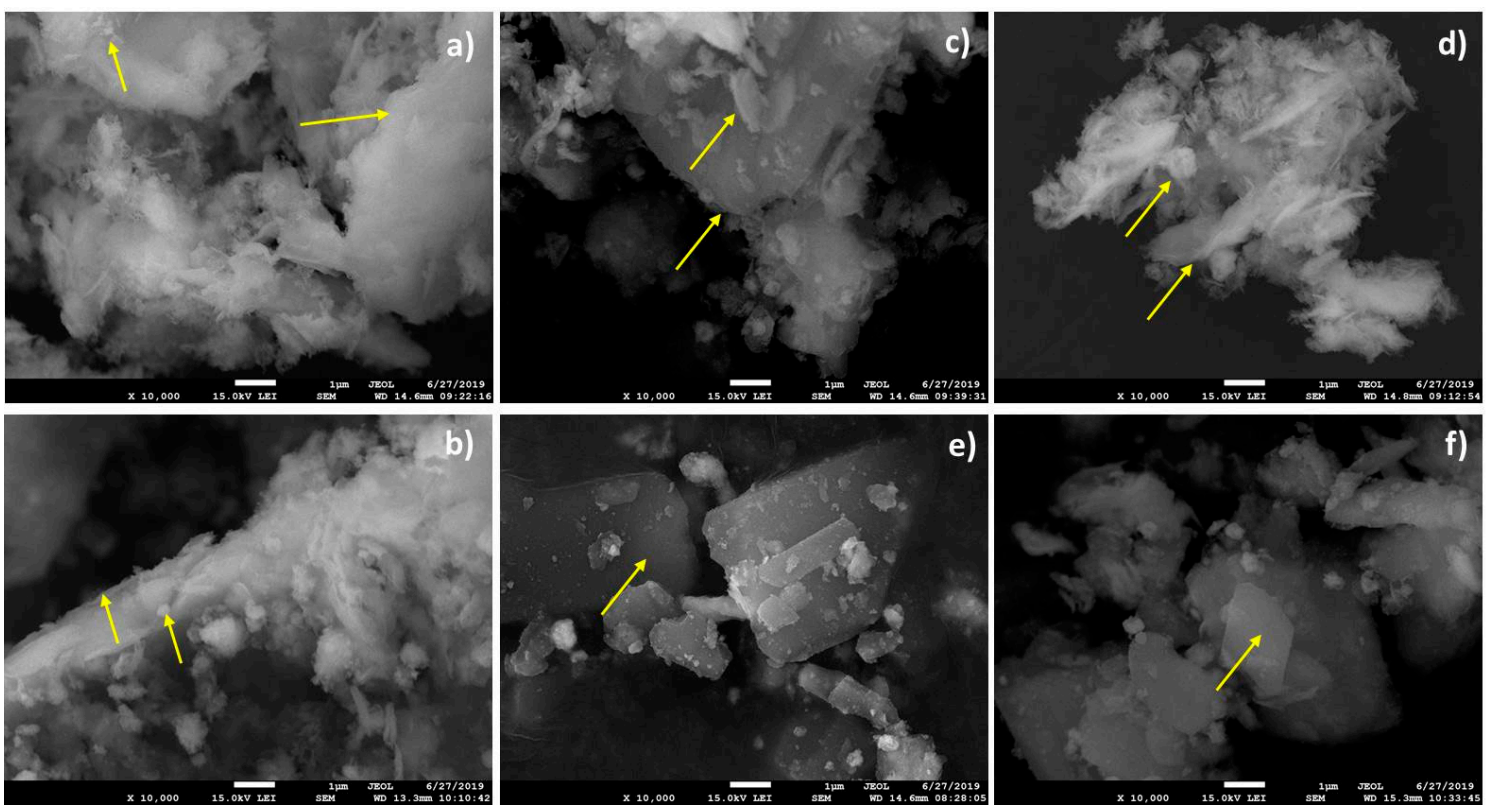

Figure 1. STEM images of the $\mathrm{ZnO} / \mathrm{V}$ (a) and hybrid nanocomposite samples: (b) ZnO/V_M_CH, (c) $\mathrm{ZnO} / \mathrm{V} \_30 \mathrm{U} \_\mathrm{CH}$, (d) $\mathrm{ZnO} / \mathrm{V} \_90 \mathrm{U} \_\mathrm{CH},(\mathbf{e}) \mathrm{ZnO} / \mathrm{V} \_30 \mathrm{U} \_\mathrm{CH}$.R, and (f) $\mathrm{ZnO} / \mathrm{V} \_90 \mathrm{U}$-CH_R.

The mechanical intercalation of $\mathrm{CH}$ (Figure 1b, sample ZnO/V_M_CH) had no significant effect on the particle morphology changes; the particles also formed agglomerates. It can be assumed that the $\mathrm{CH}$ produces the thin film that coats the original $\mathrm{ZnO} / \mathrm{V}$ particles.

The ultrasonic intercalation of $\mathrm{CH}$ in a beaker produced the rounded and frayed edges of nanocomposite particles (Figure 1c,d). The bigger and smaller particle fractions, which are separated from each other, are evident. The particle surfaces are composed of individual platelets with sharp edges and are smooth without the evident presence of $\mathrm{ZnO}$ nanoparticles. The samples prepared in a Roset's vessel (Figure 1e,f) produced particles with a representative lamellar structure and smooth surface. This can be attributed to the intense movement of nanocomposite particles in the liquid phase (water) and the washout/removal of $\mathrm{ZnO}$ nanoparticles from vermiculite surfaces. The $\mathrm{CH}$ caused clarification of vermiculite edges as a result of $\mathrm{CH}$ intercalation.

\subsection{X-ray Diffraction Analysis}

The XRD pattern of sample $\mathrm{ZnO} / \mathrm{V}$ shows reflections with interlayer distance values of $d=1.224$ $\mathrm{nm}, 1.135 \mathrm{~nm}$, and $1.001 \mathrm{~nm}$ (Figures $2 \mathrm{a}$ and 3a). The interlayer distance $d=1.224 \mathrm{~nm}$ signifies that $\mathrm{ZnO}$ nanoparticles can be incorporated into the vermiculite interlayer $[23,24]$. The $d=1.001 \mathrm{~nm}$ belongs to the dehydrated phase of the vermiculite structure and $d=1.135 \mathrm{~nm}$ indicates a different hydration state with a different amount of water molecules. The values $d=0.477 \mathrm{~nm}, 0.328 \mathrm{~nm}, 0.154 \mathrm{~nm}$, and 
$0.444 \mathrm{~nm}$ belong to the vermiculite reflections. The reflections with $d=0.842 \mathrm{~nm}$ and $0.312 \mathrm{~nm}$ are ascribed to the admixture phase in vermiculite [25].
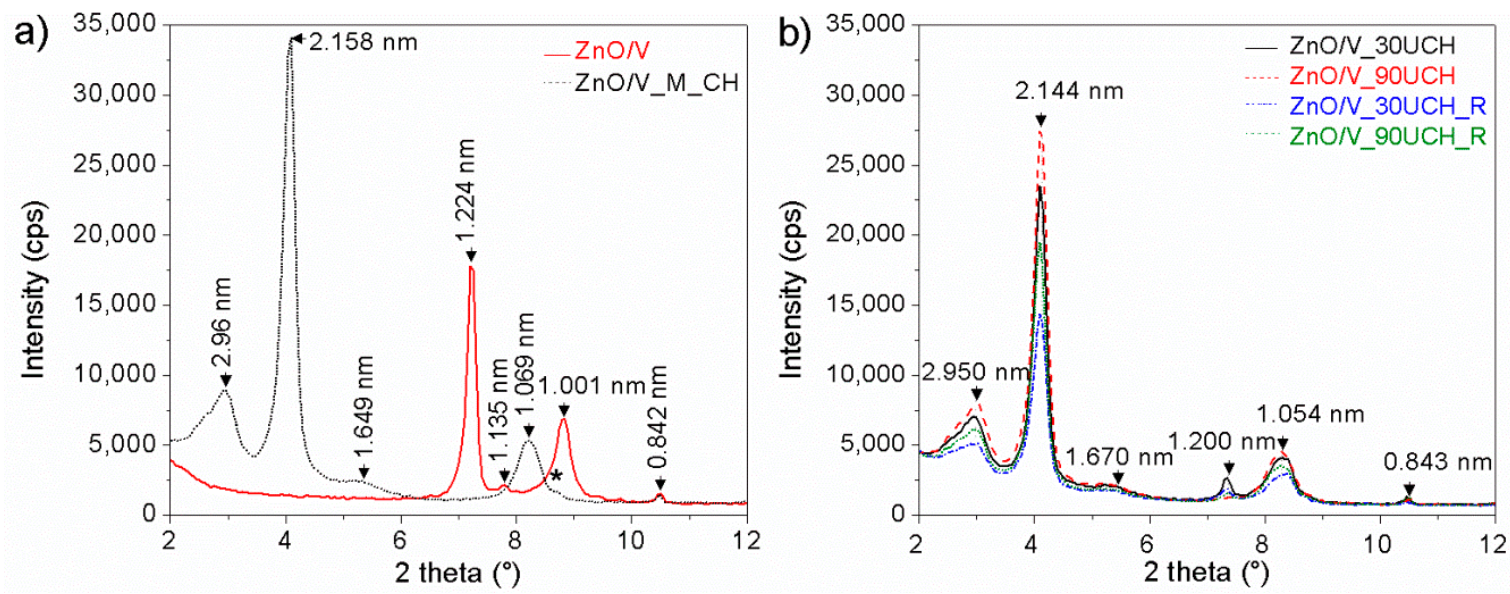

Figure 2. XRD patterns (from $2^{\circ}$ to $12^{\circ} 2 \theta$ ) of samples (a) $\mathrm{ZnO} / \mathrm{V}$ and $\mathrm{ZnO} / \mathrm{V} \_\mathrm{M} \_\mathrm{CH}$ and (b) ZnO/V_30U_CH, ZnO/V_90U_CH, ZnO/V_30U_CH_R and ZnO/V_90U_CH.
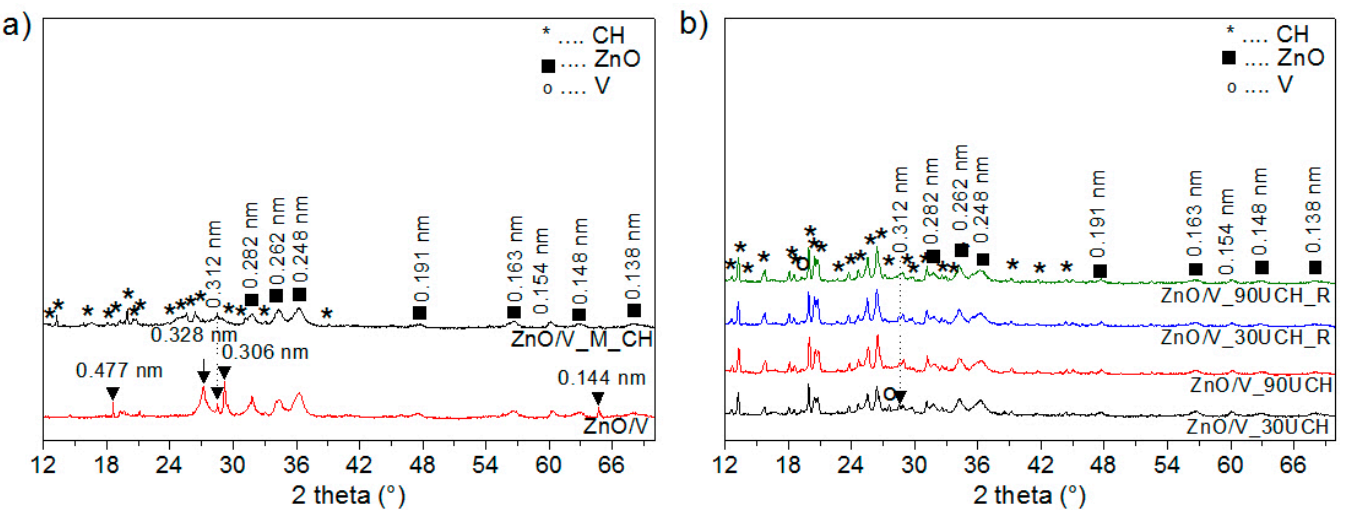

Figure 3. XRD patterns (from $12^{\circ}$ to $70^{\circ} 2 \theta$ ) of hybrid nanocomposite samples (a) $\mathrm{ZnO} / \mathrm{V}$ and ZnO/V_M_CH and (b) ZnO/V_30U_CH, ZnO/V_90U_CH, ZnO/V_30U_CH_R and ZnO/V_90U_CH.

Reflections for the hexagonal wurzite structure of $\mathrm{ZnO}$ (PDF card no. 01-079-2205) were confirmed on the XRD-pattern of $\mathrm{ZnO} / \mathrm{V}$ at $2 \theta=31.80^{\circ}, 34.17^{\circ}, 36.22^{\circ}, 47.60^{\circ}, 56.56^{\circ}$, and $62.81^{\circ}$, and $68.06^{\circ}$ corresponds to $d$-values $0.282 \mathrm{~nm}, 0.262 \mathrm{~nm}, 0.248 \mathrm{~nm}, 0.191 \mathrm{~nm}, 0.163 \mathrm{~nm}, 0.148 \mathrm{~nm}$, and $0.138 \mathrm{~nm}$.

After treatment of $\mathrm{ZnO} / \mathrm{V}$ with $\mathrm{CH}$ by mechanical stirring (Figures 2a and 3a), new reflections appeared for sample ZnO/V_M_CH. The interlayer distance values $d=2.96 \mathrm{~nm}, 2.158 \mathrm{~nm}, 1.649 \mathrm{~nm}$, and $1.069 \mathrm{~nm}$ correspond to these reflections, which confirms the expansion of interlayer space of vermiculite due to intercalation of $\mathrm{CH}[12,26]$. Moreover, the XRD pattern confirms the reflections of non-intercalated $\mathrm{CH}$ on the surface of the $\mathrm{V}$ substrate. $\mathrm{ZnO}$ reflections were also confirmed on the XRD pattern of ZnO/V_M_CH.

The XRD patterns of nanocomposites with $\mathrm{CH}$ intercalated by ultrasonic method (Figures $2 \mathrm{~b}$ and $3 \mathrm{~b}$ ) show reflections with interlayer distance values of $d=2.950 \mathrm{~nm}, 2.144 \mathrm{~nm}, 1.670 \mathrm{~nm}, 1.200$, and $1.054 \mathrm{~nm}$. There are only very small shifts in the comparison with ZnO/V_M_CH, which may be related to the arrangement of molecules in the interlayer as a result of the lower content of interlayer cations after ultrasonic intercalation, which was confirmed by XRFS analysis.

Based on the intensity of $\mathrm{CH}$ reflections on the vermiculite surface, the samples with $\mathrm{CH}$ intercalated by ultrasonic method contained the higher amounts of $\mathrm{CH}$ on the vermiculite surface in comparison with $\mathrm{ZnO} / \mathrm{V}_{-} \mathrm{M}_{-} \mathrm{CH}$. These results also correspond with the $f_{\text {oc }}$ analysis, which confirmed a higher amount of $f_{\mathrm{oc}}$ in these samples. The ultrasonic action can cause greater disruption of the 
vermiculite surface structure due to the strong cavitation action, contributing to the formation of new areas on which a higher amount of $\mathrm{CH}$ is attached.

Nanocomposites with $\mathrm{CH}$ intercalated by the ultrasonic method for $30 \mathrm{~min}$ or $90 \mathrm{~min}$ in two types of vessels, the beaker and the Roset's vessel, did not show significant differences. Samples prepared for $90 \mathrm{~min}$ showed higher relative intensity compared with those prepared for $30 \mathrm{~min}$. Samples prepared in the Roset's vessel showed lower relative intensity compared with samples prepared in the beaker.

The crystallite size $\left(L_{c}\right)$ of $\mathrm{ZnO}$ in the samples was calculated based on (101) reflection (about $36.2^{\circ}$ $2 \theta)$ according the Scherrer's equation [27]. The highest $L_{\mathrm{c}}$ value showed in sample $\mathrm{ZnO} / \mathrm{V}(8.41 \mathrm{~nm})$. After mechanical intercalation of $\mathrm{CH}$, the $L_{\mathrm{c}}$ value of $\mathrm{ZnO}$ decreased to $7.71 \mathrm{~nm}$ for $\mathrm{ZnO} / \mathrm{V} \_\mathrm{M} \_\mathrm{CH}$. After ultrasonic intercalation of $\mathrm{CH}$, the $L_{\mathrm{c}}$ value of $\mathrm{ZnO}$ decreased to $7.11 \mathrm{~nm}$ for $\mathrm{ZnO} / \mathrm{V} \_30 \mathrm{U} \_\mathrm{CH}$, ZnO/V_30U_CH_R, and ZnO/V_90U_CH_R and to 7.05 nm for ZnO/V_30U_CH.

\subsection{FTIR Spectroscopy}

The IR spectrum of $\mathrm{ZnO} / \mathrm{V}$ (Figure 4) shows bands at 3698 and $3439 \mathrm{~cm}^{-1}$ in the $\mathrm{OH}$ stretching region attributed to structural $\mathrm{OH}$ groups of $\mathrm{V}$, and adsorbed water there to $\mathrm{OH}$ bending vibration at $1631 \mathrm{~cm}^{-1}$ also characterizes adsorbed water. The intensive band at $1002 \mathrm{~cm}^{-1}$ is assigned to Si-O stretching vibration, together with $\mathrm{Si}-\mathrm{O}$ bending vibration at $453 \mathrm{~cm}^{-1}$, which overlaps the $\mathrm{Zn}-\mathrm{O}$ band that occurs in a similar position $[24,28]$.

Since spectra of all prepared $\mathrm{ZnO} / \mathrm{V} / \mathrm{CH}$ nanocomposites show vibrations characterizing the presence of $\mathrm{CH}$ at almost the same positions, differing only by intensities, we selected two samples where $\mathrm{CH}$ was intercalated by the mechanical method (ZnO/V_M_CH, Figure 4) and one by the ultrasonic methods (ZnO/V_90U_CH, Figure 4). The presence of $\mathrm{CH}$ in these nanocomposites was confirmed by the following vibrations: 3316 (3311), 3200 (3196), and $3120(3124) \mathrm{cm}^{-1}$, which correspond to $\mathrm{NH}$ stretching vibrations of secondary amine and imine functional groups, and by two bands at 2937 (2938) and $2858(2856) \mathrm{cm}^{-1}$, which are assigned to asymmetric and symmetric C-H stretching bands of $\mathrm{CH}$. C-N stretching vibration of the imine group appeared at $1637(1636) \mathrm{cm}^{-1}$. The bands occurring at region $1604-1416 \mathrm{~cm}^{-1}$ originate from $\mathrm{N}-\mathrm{H}$ bending vibration of secondary amine and imine groups and further from the stretching $C-C$ vibrations of aromatic rings. Finally, bands at 824 $\mathrm{cm}^{-1}$ belong to the $\mathrm{C}-\mathrm{H}$ out-of-plane deformation rocking vibration of methylene groups [24,29].

Figure 5 shows comparisons of band intensities in the FTIR spectra of $\mathrm{ZnO} / \mathrm{V} / \mathrm{CH}$ nanocomposites prepared via different methods. In the region $3500-1100 \mathrm{~cm}^{-1}$, mainly including $\mathrm{C}-\mathrm{H}$ and $\mathrm{N}-\mathrm{H}$ stretching and bending vibrations of $\mathrm{CH}$, we can observe increasing intensities of the characteristic $\mathrm{CH}$ bands from samples prepared by the mechanical method (ZnO/V_M_CH) compared to those prepared by the ultrasonic methods, which is in very good agreement with results from analysis of total organic carbon content. Moreover, in the region below $1100 \mathrm{~cm}^{-1}$, where there are predominantly characteristic bands of $\mathrm{V}$, we can observe a decrease in the characteristic $\mathrm{V}$ bands from samples prepared via mechanical method compared to those prepared by ultrasonic methods. 

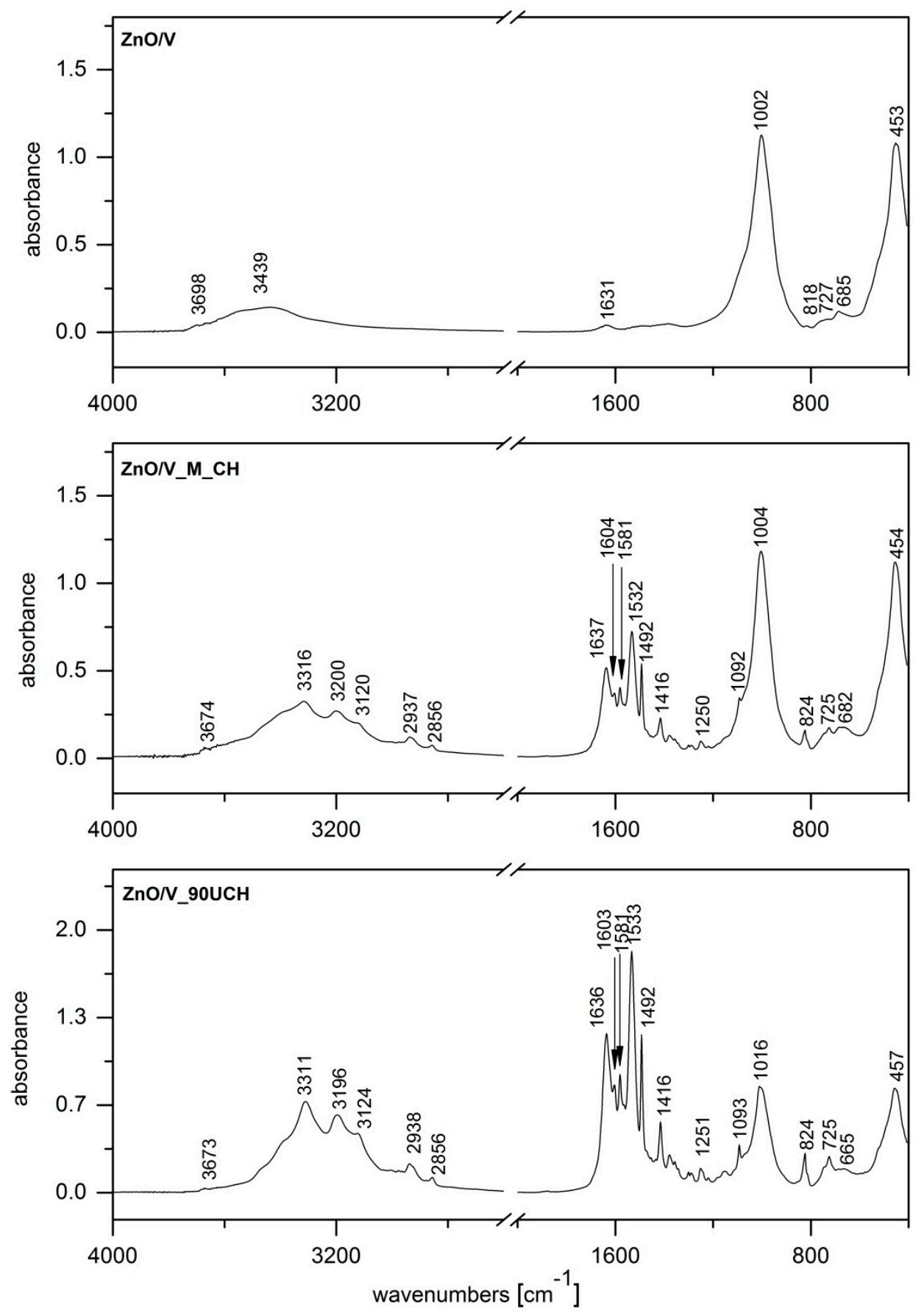

Figure 4. FTIR spectra of $\mathrm{ZnO} / \mathrm{V}, \mathrm{ZnO} / \mathrm{V} \_\mathrm{M} \_\mathrm{CH}$, and $\mathrm{ZnO} / \mathrm{V} \_90 \mathrm{UCH}$.

\subsection{Particle Size and Surface Characteristics}

The particle size distributions (PSD) in the volume content are shown in Figure 6 for all experimental samples. The particle size (PS) parameters were measured by the laser diffraction method in liquid mode. The PS parameters (Table 2), obtained from the particle size distribution data, were: volume-weighted mean diameter (De Brouckere mean diameter $\left(d_{43}\right)$ and mode diameter $\left(d_{\mathrm{m}}\right)$ ), which corresponds to the maximum peak of the frequency distribution. 


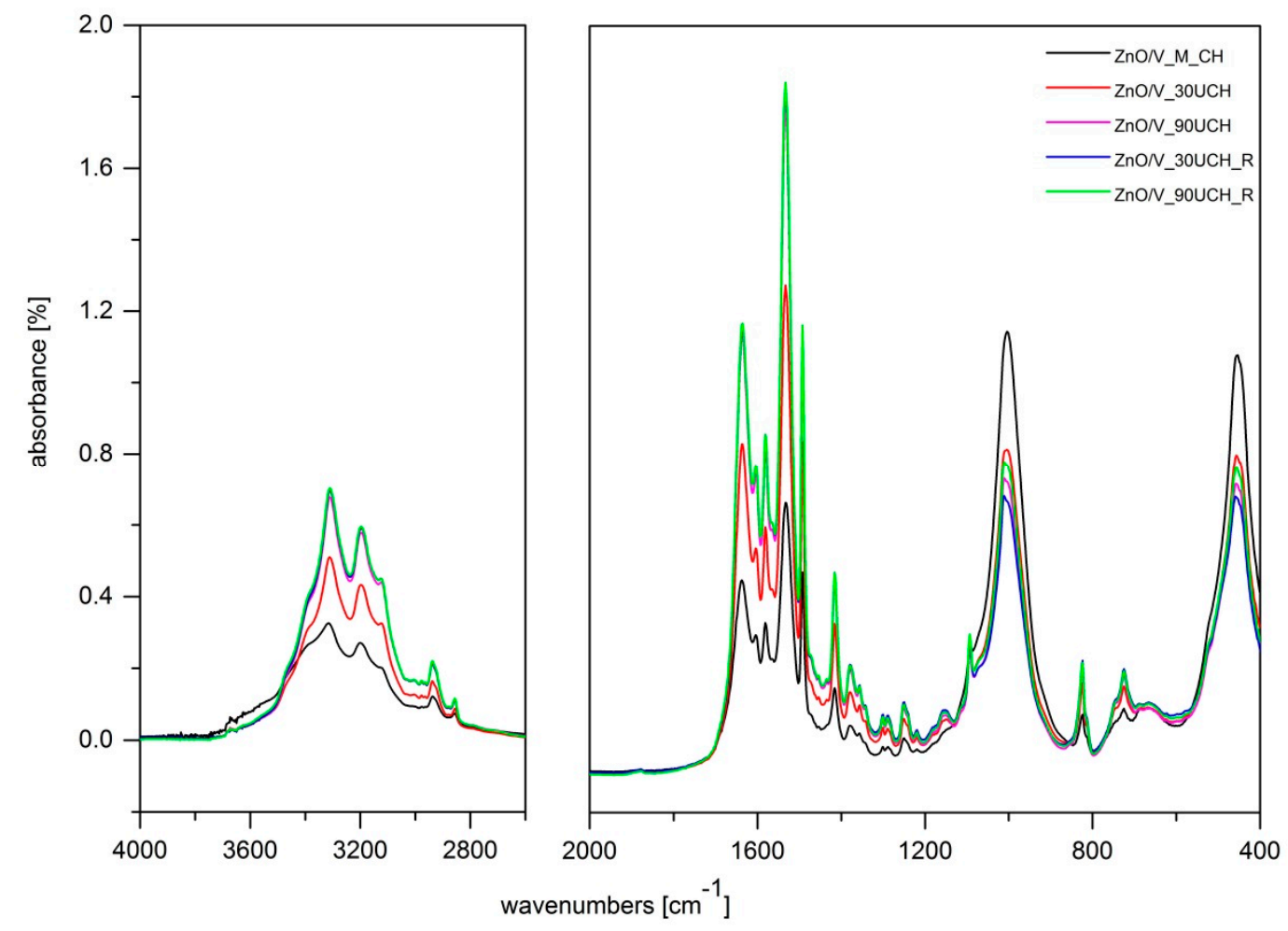

Figure 5. Comparison of band intensities-FTIR spectra of $\mathrm{ZnO} / \mathrm{V} / \mathrm{CH}$ nanocomposites prepared by different methods.

a)

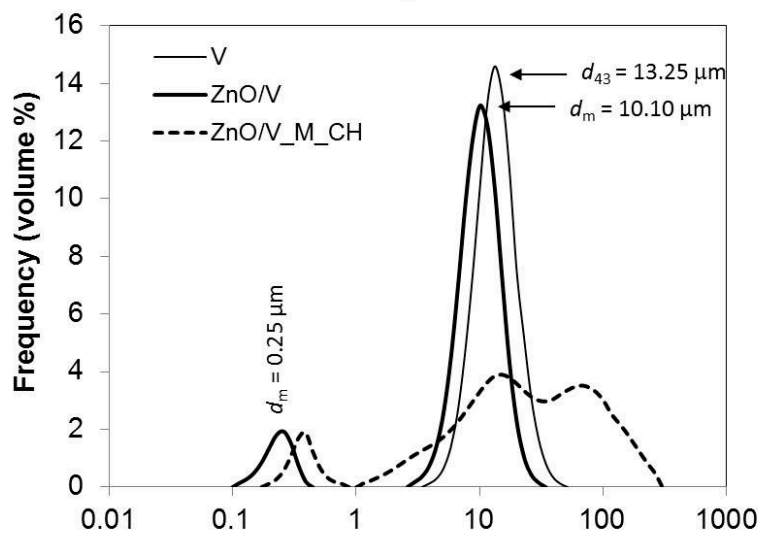

b)

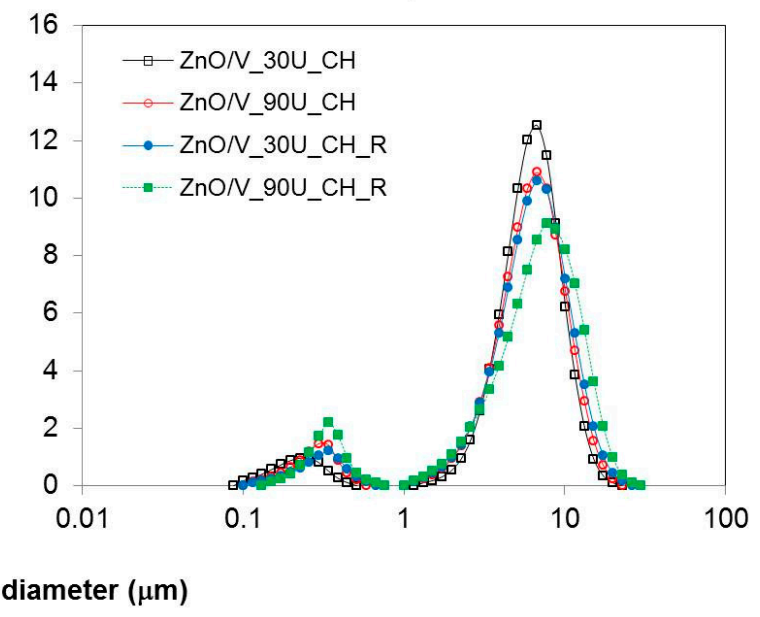

Figure 6. Log-normal particle size distribution of the (a) $\mathrm{V}, \mathrm{ZnO} / \mathrm{V}$, and $\mathrm{ZnO} / \mathrm{V} \_\mathrm{M} \_\mathrm{CH}$ and (b) ZnO/V_30U_CH, ZnO/V_90U_CH, ZnO/V_30U_CH_R, and ZnO/V_90U_CH_R nanocomposite samples. 
Table 2. Particle size and surface parameters.

\begin{tabular}{cccccc}
\hline Samples & $\begin{array}{c}d_{\mathrm{m}} \\
{[\mu \mathrm{m}]}\end{array}$ & $\begin{array}{c}\boldsymbol{d}_{\mathbf{4 3}} \\
{[\mu \mathrm{m}]}\end{array}$ & $\begin{array}{c}\text { SSA } \\
{\left[\mathbf{m}^{2} \cdot \mathbf{g}^{-1}\right]}\end{array}$ & $\begin{array}{c}\mathbf{P V} \\
{\left[\mathrm{cm}^{3} \cdot \mathbf{g}^{-1}\right]}\end{array}$ & $\begin{array}{c}\xi-P o t e n t i a l \\
{[\mathbf{m V}]}\end{array}$ \\
\hline $\mathrm{V}$ & 13.25 & 13.48 & 93.18 & 0.107 & -60.0 \\
\hline ZnO/V & $\begin{array}{c}0.25 \\
10.10\end{array}$ & 9.07 & 22.99 & 0.030 & -20.6 \\
\hline ZnO/V_M_CH & $\begin{array}{c}0.39 \\
15.17\end{array}$ & 39.37 & 22.02 & 0.031 & 27.7 \\
\hline ZnO/V_30U_CH & $\begin{array}{c}0.23 \\
6.72\end{array}$ & 5.83 & 17.69 & 0.026 & 23.4 \\
\hline ZnO/V_90U_CH & $\begin{array}{c}0.30 \\
6.72\end{array}$ & 5.89 & 15.23 & 0.020 & 23.9 \\
\hline ZnO/V_30U_CH_R & $\begin{array}{l}0.34 \\
6.72\end{array}$ & 6.19 & 14.46 & 0.026 & 23.4 \\
\hline ZnO/V_90U_CH_R & $\begin{array}{l}0.34 \\
7.70\end{array}$ & 6.69 & 14.49 & 0.024 & 23.9 \\
\hline
\end{tabular}

The particle size distributions of the samples show modal and bimodal characteristics. The narrow monomodal PSD with a mean diameter of $d_{43}=13.25 \mu \mathrm{m}$ was measured for the natural $\mathrm{V}$ sample, which was used as a starting material (Figure 6a). The sonochemically prepared $\mathrm{ZnO} / \mathrm{V}$ nanocomposite sample led to a decrease in the PS $\left(d_{43}=9.07 \mu \mathrm{m}\right)$, but it gave rise to a bimodal characteristic of PSD. However, a very narrow PSD in the area of higher size fractions was retained. This confirms the presence of two size fractions with mode diameters of $d_{\mathrm{m}}=0.25 \mu \mathrm{m}$ and $d_{\mathrm{m}}=10.10 \mu \mathrm{m}$. These results correspond to the structural changes on the $\mathrm{V}$ particles (as seen in the SEM images, Figure 1).

From a particle size analysis point of view, mechanical intercalation of $\mathrm{CH}$ had an effect on the particle behavior in the sample volume (ZnO/V_M_CH, Figure 6a). The PSD had a bimodal characteristic with two mode diameters of $0.39 \mu \mathrm{m}$ and $15.17 \mu \mathrm{m}\left(d_{\mathrm{m}}\right)$, whereby interaction in higher size fractions (particle agglomeration) is evident. While the distribution range for the $\mathrm{ZnO} / \mathrm{V}$ sample was in the range of $2.60 \mu \mathrm{m}$ to $34.26 \mu \mathrm{m}$ (Figure 6a), after mechanical intercalation of $\mathrm{CH}$, the interval is much wider; from $1.15 \mu \mathrm{m}$ to $300.52 \mu \mathrm{m}$ (ZnO/V_M_CH, Figure 6a). It corresponds to the SEM images, where agglomeration and/or coagulation behavior were confirmed.

The ultrasonic intercalation of $\mathrm{CH}$ resulted in the reduction and arrangement of PS to the mean diameter $d_{43}=5.83 \mu \mathrm{m}$ for $\mathrm{ZnO} / \mathrm{V} \_30 \mathrm{U} \_\mathrm{CH}$ (Figure $6 \mathrm{~b}$ ) and $d_{43}=6.69 \mu \mathrm{m}$ for ZnO/V_90U_CH_R, and did not affect the bimodal character of the PSD. Simultaneously, any effects of ultrasonic exposure time and the influence of the preparation conditions (in the beaker or the Roset's vessel) on the PS and PSD changes were not noticed.

The values of specific surface area (SSA) and the total pore volume (PV) were measured by nitrogen gas-adsorption and are given in Table 2. The SSA of natural V is high, $93.18 \mathrm{~m}^{2} \cdot \mathrm{g}^{-1}$, and corresponds to reported values measured by Valášková, M. et al. [21,22]. The SSA rapidly decreased with the sonochemical preparation of the $\mathrm{ZnO} / \mathrm{V}$ sample, and with the next mechanical intercalation of $\mathrm{CH}$, to a value around $22.5 \mathrm{~m}^{2} \cdot \mathrm{g}^{-1}$. The hybrid nanocomposite samples with intercalated $\mathrm{CH}$ show a similar specific surface area in interval values from $14.46 \mathrm{~m}^{2} \cdot \mathrm{g}^{-1}\left(\mathrm{ZnO} / \mathrm{V} \_30 \mathrm{U} \_\mathrm{CH}\right.$ _R $)$ to $17.69 \mathrm{~m}^{2} \cdot \mathrm{g}^{-1}$ (ZnO/V_30U_CH) and reached a maximum of $17.69 \mathrm{~m}^{2} \cdot \mathrm{g}^{-1}\left(\mathrm{ZnO} / \mathrm{V} \_30 \mathrm{U} \_\mathrm{CH}\right)$. This decrease directly correlated to the reduction in particle size and particle size distribution. This phenomena also corresponds to the PV results where decreased characteristics between mechanically and ultrasonically intercalation of $\mathrm{CH}$ is evident.

The intercalation of $\mathrm{CH}$ was realized on negatively charged surfaces with the $\xi$-potential $-20.6 \mathrm{mV}$ ( $\mathrm{ZnO} / \mathrm{V}$ sample) and led to hybrid nanocomposites with positively charged surfaces (Table 2). The differences in the $\xi$-potential of mechanically intercalated $\mathrm{CH}$ in the $\mathrm{ZnO} / \mathrm{V} \_\mathrm{M} \_\mathrm{CH}$ sample $(27.7 \mathrm{mV})$ and ultrasonic intercalation of $\mathrm{CH}$ ( $\xi$-potential from $23.4 \mathrm{mV}$ to $23.9 \mathrm{mV}$ ) are evident. They are in 
agreement with the elemental changes in the sample structures (Table 1), mainly with the decreasing of $\mathrm{ZnO}, \mathrm{SiO}_{2}, \mathrm{Al}_{2} \mathrm{O}_{3}$, and $\mathrm{MgO}$ and the increasing of $\mathrm{CH}$. These findings correspond with the knowledge [8] that the position of the central cations in octahedra (ideally $\mathrm{Al}^{3+}$ ) and tetrahedra (ideally $\mathrm{Si}^{4+}$ ) of vermiculites are substituted by $\mathrm{ZnO}$ and $\mathrm{CH}$, and result in the positively charged surfaces of hybrid nanocomposites.

\subsection{Antibacterial Activity}

Results of antibacterial activity (AC) measured at time intervals from $30 \mathrm{~min}$ to 1 day (at various time periods) are summarized for Gram negative strains (E. coli and P. aeruginos) in Table 3 and for Gram positive strains (S. aureus and E. faecalis) in Table 4. The AC was evaluated by finding the minimum inhibitory concentration (MIC).

Table 3. Antibacterial tests. Minimum inhibitory concentration (MIC) values ( $\% w / v)$ of the experimental samples against $E$. coli and $P$. aeruginosa strains.

\begin{tabular}{ccccccccc}
\hline \multirow{2}{*}{ Samples } & \multicolumn{4}{c}{ E. coli (MIC) } & \multicolumn{4}{c}{ P. aeruginosa (MIC) } \\
\cline { 2 - 8 } & 30 Min & 120 Min & 240 Min & 1 Day & 30 Min & 120 Min & 240 Min & 1 Day \\
\hline ZnO/V & - & - & - & - & - & - & - & - \\
ZnO/V_M_CH & 0.56 & 0.19 & 0.19 & 0.007 & 0.56 & 0.19 & 0.19 & 0.021 \\
ZnO/V_30U_CH & 0.56 & 0.19 & 0.062 & 0.007 & 0.56 & 0.19 & 0.062 & 0.007 \\
ZnO/V_90U_CH & 0.19 & 0.062 & 0.062 & 0.007 & 0.19 & 0.19 & 0.19 & 0.007 \\
ZnO/V_30U_CH_R & 0.062 & 0.062 & 0.062 & 0.007 & 0.19 & 0.062 & 0.021 & 0.021 \\
ZnO/V_90U_CH_R & 0.062 & 0.062 & 0.062 & 0.007 & 0.19 & 0.062 & 0.062 & 0.021 \\
\hline
\end{tabular}

Table 4. Antibacterial tests. MIC values $(\% w / v)$ of the experimental samples against S. aureus and E. faecalis strains.

\begin{tabular}{ccccccccc}
\hline \multirow{2}{*}{ Samples } & \multicolumn{4}{c}{ S. aureus (MIC) } & \multicolumn{4}{c}{ E. faecalis (MIC) } \\
\cline { 2 - 8 } & 30 Min & 120 Min & 240 Min & 1 Day & 30 Min & 120 Min & 240 Min & 1 Day \\
\hline ZnO/V & - & - & - & - & - & - & - & - \\
ZnO/V_M_CH & 0.56 & 0.56 & 0.56 & 0.007 & 1.67 & 0.56 & 0.56 & 0.007 \\
ZnO/V_30U_CH & 0.56 & 0.56 & 0.062 & 0.007 & 1.67 & 0.19 & 0.19 & 0.007 \\
ZnO/V_90U_CH & 0.19 & 0.062 & 0.062 & 0.007 & 1.67 & 0.56 & 0.56 & 0.007 \\
ZnO/V_30U_CH_R & 0.19 & 0.19 & 0.062 & 0.007 & 0.56 & 0.19 & 0.19 & 0.007 \\
ZnO/V_90U_CH_R & 0.19 & 0.19 & 0.19 & 0.007 & 1.67 & 0.19 & 0.19 & 0.007 \\
\hline
\end{tabular}

The AC of the $\mathrm{ZnO}$ nanoparticles [18] and $\mathrm{ZnO} / \mathrm{V}$ nanocomposite samples [30], with consideration of various conditions of preparation, was studied. It was found that these nanomaterials reduced the bacterial viability of $S$. aureus and E. coli and showed strong antibacterial activity, which was fast and long-acting after $120 \mathrm{~min}$ for more than 5 days. However, in this study, when samples were prepared under ultrasound, the $\mathrm{ZnO} / \mathrm{V}$ sample was in all cases bacteria inactive (Tables 3 and 4).

All hybrid nanocomposite samples prepared by the ultrasound method showed great antibacterial activity at the beginning of antibacterial testing (after $30 \mathrm{~min}$ ) against both Gram negative strains and also against $S$. aureus. Moreover, in the case of $E$. coli, the best results were reached with both samples prepared in a Roset's vessel $(0.062 \% w / v$ MIC after $30 \mathrm{~min}$, Table 3). Slightly worse results after $30 \mathrm{~min}$ were observed against $E$. faecalis (1.67\% w/v MIC after $30 \mathrm{~min}$, Table 4$)$.

After one day of testing, almost all samples against all four strains showed the best antimicrobial efficiency $(0.007 \% w / v$ MIC, Tables 3 and 4$)$. Some samples were slightly worse against very resistant P. aeruginosa $(0.021 \% w / v$ MIC, Table 3$)$.

Generally, sample ZnO/V_M_CH, prepared by the mechanical method, possessed slightly worse AC. It is probably connected with results from the XRD analysis, which showed us that this sample had less non-intercalated $\mathrm{CH}$ than the others prepared by the ultrasound method. For this reason, bacteria have worse contact with antimicrobial agents. 


\section{Conclusions}

Antibacterial hybrid nanocomposite materials based on zinc oxide/vermiculite/chlorhexidine $(\mathrm{ZnO} / \mathrm{V} / \mathrm{CH})$ with different concentrations of the organic component (chlorhexidine dihydrochloride) were prepared under different conditions using the ultrasonic method. Morphological, phase, elemental, and surface changes were compared with mechanically prepared hybrid nanocomposite materials. Phase analysis and structure analysis were performed by X-ray diffraction (XRD) and infrared spectroscopy (FTIR). The presence of $\mathrm{CH}$ and $\mathrm{ZnO}$ was confirmed in all samples. XRD analysis confirmed that ultrasound intercalation in a beaker helps more efficiently with the intercalation of $\mathrm{CH}$ to the vermiculite $(\mathrm{V})$ interlayer space, while a Roset's vessel contributed to the attachment of the $\mathrm{CH}$ molecules to the vermiculite surface. FTIR and total carbon analysis $\left(f_{\text {oc }}\right)$ showed that longer intercalation led to higher concentrations of $\mathrm{CH}$ in the structure.

All prepared hybrid nanocomposite materials showed the presence of a high percentage of total organic carbon content, while the highest values were measured in samples intercalated by the ultrasonic method. Particle size analyses confirmed that the ultrasonic method contributed to particle size reduction and their homogenization/arrangement. Particle size reduction during the ultrasonic intercalation was higher than during the mechanical intercalation (ZnO/V_M_CH). The ultrasonic intercalation of $\mathrm{CH}$ led to the decreasing of the specific surface area (SSA) and to the preparation of the particles with sharp edges as a result of $\mathrm{CH}$ intercalation to the interlayer space of the vermiculite particles. Increasing the concentration of $\mathrm{CH}$ decreased the SSA values, and the particles were more compact. The intercalation in a Roset's vessel produced particles with lamellar structures and smooth surfaces.

The antibacterial activity of all hybrid nanocomposite materials has been demonstrated against S. aureus, E. faecalis, E. coli, and P. aeruginosa. Efficiency with very low MIC concentrations was observed after $30 \mathrm{~min}$ of exposure. The best results in this short time interval were against $E$. coli and came from samples prepared by the ultrasonic method in a Roset's vessel.

The benefit of all the samples prepared by ultrasonic method is the rapid onset of an antimicrobial effect and its long-term duration. For that reason, the ultrasonic method represents a perceptive and efficient method of antibacterial hybrid nanocomposite material preparation. Compared to conventional intercalation procedures, it is a time-saving method enabling regulation of organic matter in the structure.

Author Contributions: K.Č.B. designed the work, performed the synthesis, SEM, PSD, $\xi$-potential analysis, and the AC evaluation, wrote the original draft, revised and finalized the manuscript; S.H. performed FTIR analysis and wrote and reviewed the manuscript; K.Š. performed the synthesis; M.H. performed the XRD analysis; B.T. performed the XRFS analysis.

Funding: This work was supported by project No. SP2019/24 "Hybrid and biodegradable clay nanocomposite materials".

Acknowledgments: The authors would like to thank G. Kratošová for the SEM micrographs.

Conflicts of Interest: The authors declare no conflict of interest.

\section{References}

1. Ho, Y.S.; McKay, G. Batch Lead (II) removal from aqueous solution by peat: Equilibrium and kinetics. Trans. Chem. E Part B 1999, 77, 165-173. [CrossRef]

2. Sanchez, C.; Julián, B.; Belleville, P.; Popall, M. Applications of hybrid organic-inorganic nanocomposites. J. Mater. Chem. 2005, 15, 3559-3592. [CrossRef]

3. Húsing, N.; Hartmann, S. Inorganic-Organic Hybrid Porous Materials. In Hybrid Nanocomposites for Nanotechnology: Electronic, Optical, Magnetic and Biomedical Applications; Merhari, L., Ed.; Springer: New York, NY, USA, 2009; pp. 131-171.

4. Meroni, D.; Ardizzone, S. Preparation and Application of Hybrid Nanomaterials. Nanomaterials 2018, 8, 891. [CrossRef] [PubMed] 
5. Kalia, S.; Haldorai, Y. Organic-Inorganic Hybrid Nanomaterials; Springer: New York, NY, USA, 2015; pp. 1-379.

6. Camargo, P.H.C.; Satyanarayana, K.G.A.; Wypych, F. Nanocomposites: Synthesis, Structure, Properties and New Application Oppurtinities. Mater. Res. 2009, 12, 1-39. [CrossRef]

7. Sharifalhoseini, Z.; Entezari, M.H.; Jalal, R. Direct and indirect sonication affect differently the microstructure and the morphology of $\mathrm{ZnO}$ nanoparticles: Optical behavior and its antibacterial activity. Ultrason. Sonochem. 2015, 27, 466-473. [CrossRef] [PubMed]

8. Nguyen, A.N.; Reinert, L.; Lévewue, J.M.; Beziat, A.; Dehaudt, P.; Juliaa, J.F.; Duclaux, L. Preparation and characterization of micron and submicron-sized vermiculite powders by ultrasonic irradiation. Appl. Clay Sci. 2013, 72, 9-17. [CrossRef]

9. Perez-Rodríguez, J.L.; Pascual, J.; Franco, F.; Jiménez de Haro, M.C.; Duran, A.; Ramírez del Valle, V.; Pérez-Maqueda, L.A. The influence of ultrasound on the thermal behaviour of clay minerals. J. Eur. Ceram. Soc. 2006, 26, 747-753. [CrossRef]

10. Ali, F.; Reinert, L.; Lévêque, J.M.; Duclaux, L.; Muller, F.; Saeed, S.; Shah, S.S. Effect of sonication conditions: Solvent, time, temperature and reactor type on the preparation of micron sized vermiculite particles. Ultrason. Sonochem. 2014, 21, 1002-1009. [CrossRef]

11. Onder, E.; Sarier, N.; Ukuser, G.; Ozturk, M.; Arat, R. Ultrasound assisted solvent free intercalation of montmorillonite with PEG1000: A new type of organoclay with improved thermal properties. Thermochim. Acta 2013, 566, 24-35. [CrossRef]

12. Holešová, S.; Štembírek, J.; Bartošová, L.; Pražanová, G.; Valášková, M.; Samlíková, M.; Pazdziora, E. Antibacterial efficiency of vermiculite/chlorhexidine nanocomposites and results of the in vivo test of harmlessness of vermiculite. Mater. Sci. Eng. C 2014, 42, 466-473. [CrossRef]

13. Wu, Y.; Zhou, N.; Li, W.; Gu, H.; Fan, Y.; Yuan, J. Long-term and controlled release of chlorhexidine-copper(II) from organically modified montmorillonite (OMMT) nanocomposites. Mater. Sci. Eng. C 2013, 33, 752-757. [CrossRef] [PubMed]

14. Li, B.; Yu, S.; Hwang, J.Y.; Shi, S. Antibacterial Vermiculite Nano-Material. J. Miner. Mater. Charact. Eng. 2002, 1, 66-68.

15. Yamamoto, O.; Hotta, M.; Sawai, J.; Sasamoto, T.; Kojima, H. Infulence of powder characteristic of ZnO on antibacterial activity. J. Ceram. Soc. Jpn. 1998, 106, 1007-1011. [CrossRef]

16. Nair, S.; Sasidharan, A.; Divya Rani, V.V.; Menon, D.; Nair, S.; Manzoor, K.; Raina, S. Role of size scale of ZnO nanoparticles and microparticles on toxicity toward bacteria and osteoblast cancer cells. J. Mater. Sci. Mater. Med. 2009, 20, 235-241. [CrossRef] [PubMed]

17. Aydin Sevinç, B.; Hanley, L. Antibacterial activity of dental composites containing zinc oxide nanoparticles. J. Biomed. Mater. Res. B 2010, 94, 22-31. [CrossRef] [PubMed]

18. Čech Barabaszová, K.; Hundáková, M.; Mackovčáková, M.; Pazdziora, E. Three methods for antibacterial ZnO nanoparticles preparation. Mater. Today Proc. 2018, 5, S11-S19. [CrossRef]

19. Kumara, R.; Umarb, A.; Kumara, G.; Nalwad, H.S. Antimicrobial properties of ZnO nanomaterials: A review. Ceram. Int. 2017, 43, 3940-3961. [CrossRef]

20. Barabaszová, K.Č.; Rajhelová, H.; Smijová, J.; Hundáková, M. Toxicity of the Zinc Oxide and Vermiculite/Zinc Oxide Nanomaterials. J. Nanosci. Nanotechnol. 2019, 19, 2977-2982. [CrossRef]

21. Valášková, M.; Tokarský, J.; Čech Barabaszová, K.; Matějka, V.; Hundáková, M.; Pazdziora, E.; Kimmer, D. New aspects on vermiculite filler in polyethylene. Appl. Clay Sci. 2013, 72, 110-116. [CrossRef]

22. Čech Barabaszová, K.; Valášková, M. Characterization of vermiculite particles after different milling techniques. Powder Technol. 2013, 239, 277-283. [CrossRef]

23. Sani, H.A.; Ahmad, M.B.; Hussein, M.Z.; Ibrahim, N.A.; Musa, A.; Saleh, T.A. Nanocomposite of ZnO with montmorillonite for removal of lead and copper ions from aqueous solutions. Process Saf. Environ. 2017, 109, 97-105. [CrossRef]

24. Čech Barabaszová, K.; Holešová, S.; Hundáková, M.; Pazdziora, E.; Ritz, M. Antibacterial LDPE Nanocomposites Based on Zinc Oxide Nanoparticles/Vermiculite Nanofiller. J. Inorg. Organomet. Polym. Mater. 2017, 27, 986-995.

25. Valášková, M.; Kupková, J.; Simha Martynková, G.; Seidlerová, J.; Tomášek, V.; Ritz, M.; Kočí, K.; Klemm, V.; Rafaja, D. Comparable study of vermiculites from four commercial deposits prepared with fixed ceria nanoparticles. Appl. Clay Sci. 2018, 151, 164-174. [CrossRef] 
26. Samlíková, M.; Holešová, S.; Hundáková, M.; Pazdziora, E.; Jankovič, L'.; Valášková, M. Preparation of antibacterial chlorhexidine/vermiculite and release study. Int. J. Miner. Process. 2017, 159, 1-6. [CrossRef]

27. Scherrer, P. Bestimmung der Größe und der inneren Struktur von Kolloidteilchen mittels Rontgenstrahlen. Nachr. Ges. Wiss. Gott. 1918, 2, 98-100.

28. Farmer, V.C. The Layer Silicates. In The Infrared Spectra of Minerals; Mineralogical Society: London, UK, 1974.

29. Socrates, G. Infrared and Raman Characteristic Group Frequencies: Tables and Charts, 3rd ed.; John Wiley \& Sons: Chichester, UK, 2001.

30. Čech Barabaszová, K.; Hundáková, M.; Pazdziora, E. The Influence of zinc oxide concentration on antibacterial activity of the vermiculite nanocomposite. In Proceedings of the 8 th International Conference on Nanomaterials-Research and Application (NANOCON), Brno, Czech Republic, 19-21 October 2016; pp. 467-472.

(C) 2019 by the authors. Licensee MDPI, Basel, Switzerland. This article is an open access article distributed under the terms and conditions of the Creative Commons Attribution (CC BY) license (http://creativecommons.org/licenses/by/4.0/). 